\title{
Meza Márquez, Consuelo y Aída Toledo Arévalo (2015). La escritura de POETAS MAYAS CONTEMPORÁNEAS PRODUCIDA DESDE EXCÉNTRICOS ESPACIOS IDENTITARIOS. Aguascalientes: Universidad Autónoma de Aguascalientes.
}

\author{
Krishna Naranjo-Zavala
}

$\Psi^{1}$ libro La escritura de poetas mayas contemporáneas producida desde excéntricos espacios identitarios es el resultado de una exhaustiva investigación sobre las voces activas en la literatura guatemalteca. Consuelo Meza y Aída Toledo hacen partícipes a los lectores de este horizonte de poetas mayas, considerando que sus propuestas literarias surgen de contextos socioculturales, cosmovisiones y lenguas determinados. Si bien estos factores intervienen en mayor o menor medida en todo proceso de escritura creativa, en ellas impactan doblemente.

Este trabajo no sólo aporta una selección poética, va más allá: revela cómo las mujeres mayas interiorizan su quehacer literario en relación con su identidad, tema por sí mismo complejo. Porque, hay que decirlo, no existe una literatura indígena escrita por mujeres, sino expresiones poéticas heterogéneas producidas en lengua materna o en español; ha de aclararse que algunas se expresan en un idioma sin por ello renunciar a su condición indígena o mestiza. Cada una construye "lo maya" en razón de sus experiencias, deseos, inquietudes y reclamos.

Asimismo, se despejan estereotipos anclados en estas creaciones, empezando por el hecho de que asumirse maya no necesariamente implica hablar una de las lenguas originarias como el k'iche' o el q'eqchi'.
En algunos casos, el español es la lengua materna de mujeres indígenas, por la que expresan ese imaginario étnico, situación que nos obliga a movilizar nuestro "concepto" de lo maya. Por otra parte, hablantes de las lenguas mayas encaran cierta tensión al articularlas, en un clima lastimado por la desigualdad social, el racismo y la marginación. Incluso varias poetas han sido encaminadas, desde el seno familiar, a expresarse en español.

Las autoras, en una labor titánica, entrevistaron a gran parte de las mujeres guatemaltecas cuyos testimonios se incluyen en esta investigación. Así, pueden leerse en el libro las vicisitudes que las poetas han sorteado a lo largo de su vida, sus logros y sus búsquedas de diversa índole - personales, políticas o espirituales - mediante la escritura.

¿Qué implica concebirse como poeta maya?, ¿escribir sobre temas considerados emblemas de lo maya?, iextender, inevitablemente, un canto a la Madre Tierra? No siempre. La poesía de estas mujeres, aunque comparte rasgos importantes, germina de una situación específica. Sin embargo, hay una directriz: la escritura es política, es revolucionaria. Escribir es descolonizarse, verse a sí mismas, problematizar alrededor de la identidad, adquirir conciencia de sus múltiples roles. Algunas son madres, estudiantes, maestras, promotoras culturales, guías espirituales.

Krishna Naranjo Zavala. Profesora y coordinadora académica de la Licenciatura en Letras Hispanoamericanas de la Universidad de Colima. Correo electrónico: krish@ucol.mx.

Recibida: 30 de junio de 2017. 
Hacer poesía es exigir libertad de articular la lengua materna, exhibir los monstruos engendrados por un sistema dominante que ha dejado huellas catastróficas en el medioambiente a través, por ejemplo, de las hidroeléctricas y las empresas mineras. También desde lo erótico se explora la "otra" manera de enunciar el deseo, eliminando prejuicios establecidos sobre los cuerpos femeninos. Este punto es crucial dado que uno de los objetivos de las autoras es proponer estas expresiones dentro de los estudios de género. Este canto liberador, este canto de reclamo, puede vislumbrarse en el poema "Nuestras abuelas parieron mujeres libres" de Norma Chamalé:

Libre la mujer-madre que decidió dar a luz una vida. Libre la mujer convertida en madre por una violación sexual.

Libre la mujer que decide no ser madre.

Libre la mujer-hija.

Libre la mujer que sobrevivió a la guerra.

Libre la mujer-madre que le enseñó a sus hijas e hijos a exigir justicia.

Libre la mujer asesinada, torturada, violada, desaparecida

por el militar asesino.

Libre la mujer que exige justicia por el amor muerto o desaparecido.

Libre la mujer que hoy es madre y sigue siendo hija, y aprendió de

la guerra.

Libre la mujer que se organiza y lucha frente al hambre, la pobreza,

la injusticia...

Libre la mujer valiente y firme frente a la mina, la hidroeléctrica, la

Corte... (pp. 117-118).

En cuanto a la estructura del libro, se organiza en cuatro capítulos: I. "Del otro lado de la línea: antecedentes de la escritura de mujeres mayas del siglo XX"; II. "Un estado de la cuestión: etnicidad, identidad, resistencia, matrilinealidad y utopía”; III. "Maya Cu Choc y Rosa Chávez: dos momentos de la escritura de mujeres mayas", y IV. "Textualidades de escritoras mayas en el siglo XXI: acerca de un corpus inédito". En los anexos aparecen dos entrevistas: a Maya $\mathrm{Cu}$ Choc y a Rosa Chávez Juárez.

Cabe señalar que en el primer capítulo se registran con nitidez las genealogías escriturales: Luis de Lión (1939-1984) y Francisco Morales Santos, ambos kaqchikeles, son originarios de comunidades vinculadas con Antigua Guatemala, que fue capital del reino de Guatemala. Señalan las autoras que su poesía escrita en español toca diversas problemáticas que atestiguan los mayas de nuestros tiempos. Concretamente, Poemas del volcán de agua (1998) de Lión es, en palabras de Meza y Toledo, "el antecedente directo de las textualidades mayas del siglo XXI" (p. 20). El segundo publicó su primer poemario en 1961, y fue el primer autor maya en publicar un libro de este género en la época moderna (p. 22).

Por su parte, la trilingüe Calixta Gabriel Xiquin, también kaqchikel, autora de Hueso de la tierra (1996) y Tejiendolos sucesosenel tiempo/Weaving Events in Time (2002), fue la primera escritora maya que publicó un libro. Con un agudo sentido crítico frente a la denominada inclusión de los pueblos originarios desde visiones occidentales, su poesía expone la veta social de la literatura.

Seguramente las investigadoras enfrentaron un arduo proceso de investigación a fin de preparar un corpus de la poesía maya guatemalteca escrita por mujeres. Como caso particular se menciona a Rigoberta Menchú, cuya incursión en la escritura ha suscitado diferentes puntos de vista, pero el género del testimonio que ha cultivado permite ensanchar el canon nacional de las letras mayas y admitir que, desde luego, la escritura posee implicaciones políticas.

Es en el segundo capítulo donde aparece la panorámica de voces: veintinueve mujeres que han sido tratadas por la crítica literaria desde inicios del siglo XX. Nacidas entre 1953 y 1980, con una brecha generacional significativa entre ellas, resulta interesante conocer cómo asumen su quehacer poético; unas se identifican como escritoras, otras consideran la escritura como un vehículo para expresar su interior o recuperar la fuerza 
combativa de los pueblos originarios que luchan por la justicia y el reconocimiento.

Algunas de las escritoras son: María Elena Nij Nij, Calixta Gabriel Xiquín, Saq Ch'umil, Adela Delgado Pop, Maya Cu Choc, Dorotea Gómez, Rosa Chávez Juárez, Angélica María Macario, Valentina Gómez Argueta, Lucrecia García Durán, Feliciana Ujpán y Gladys Eunice Yax Tzul.

El trabajo de Consuelo Meza y Aída Toledo resulta particularmente enriquecedor para los estudios sobre la literatura indígena contemporánea porque ofrece, con suma claridad, un estudio amplio sobre la escritura de mujeres comprometidas con sus entornos, en la búsqueda o afirmación de sus identidades. Por último, creo que esta investigación motiva a realizar un acercamiento paralelo hacia las poetas mayas del sureste mexicano como Briceida Cuevas Cob, Ruperta Bautista o Juana Karen Peñate. Contamos con voces auténticas que, desde sus espacios identitarios, lanzan la palabra como un acto estético y revolucionario. 